\title{
Characteristics of solar energy radiation on typical summer and winter days in Kuwait
}

\author{
M.A. Bou-Rabee ${ }^{1}$, S.A. Sulaiman ${ }^{2}$, G. Choe ${ }^{3}$, D. Han ${ }^{3}$, T. Saeed ${ }^{4}$ and S. Marafie ${ }^{5}$ \\ ${ }^{1}$ PAAET Dept. of Electrical Eng. College of Technological Studies Kuwait \\ "Email: m.rabee@paaet.edu.kw \\ Phone: +965 60077567; Fax: +965 24816568 \\ ${ }^{2}$ Department of Mechanical Engineering, Universiti Teknologi Petronas, \\ Tronoh, Malaysia \\ ${ }^{3}$ Electrical Eng. Konkuk University, Seoul, Korea \\ ${ }^{4}$ PAAET, Science Department, College of Basic Education, Kuwait \\ ${ }^{5}$ Director, Dept. of Studies \& Research, Ministry of Electricity \& Water, Kuwait
}

\begin{abstract}
The energy received by solar collectors for power generation is limited to various conditions. The average data on solar irradiation are normally used to determine the potential of solar energy at any location. However, the variation of solar energy due to seasonal differences could affect the actual performance of the collectors, consequently leading to poorly justified system installations, which are high in cost. In this work, the characteristics of solar energy radiation in Kuwait were studied by measuring irradiance and comparing the data of selected time periods in two extreme seasons. A pyranometer, mounted two meters above the ground on a tubular beam in a shade-free area at a solar energy laboratory in Kuwait was used to measure irradiance on three consecutive days in summer and winter. The radiation data were recorded at five-minute intervals in each season for comparison. It was found that the average irradiance energy in the winter was up to $61 \%$ less than in the summer. In addition, the study revealed that the day-to-day variation of irradiance in winter (31\%) was approximately 6.5 times higher than in the summer $(4.8 \%)$. Clearly, the operation of solar power generation systems in the area during winter would face significant day-to-day fluctuations. As a result, this would necessitate frequent operation of backup power systems in order to meet the electrical power load demand.
\end{abstract}

Keywords: Solar energy; irradiance; pyranometer; solar collector.

\section{INTRODUCTION}

The light and heat energy from the sun, also known as solar energy, is increasingly in demand given the escalating global price of fossil fuels. Known as a clean energy that has no direct release of emissions, solar energy is also seen as a good alternative energy to address problems related to the environment that result from the combustion of fossil fuels, such as the greenhouse gas problem [1,2]. Two of the most common solar energy conversion devices are the solar photovoltaic (PV) and solar thermal energy systems. Solar PV systems convert solar energy into electricity through arrays of solar cells that are mounted on surfaces that are free from shade such as roofs and open fields $[3,4]$. There are many types of solar PV cells: monocrystalline silicon cells, multi-crystalline silicon cells, thick film silicon, and amorphous silicon. By contrast with photovoltaic, 
solar thermal energy involves heating fluids through specially designed collectors for various purposes, ranging from domestic applications to steam production for electrical power generation [5]. The present technologies to extract solar energy are still regarded as expensive although the costs have been decreasing through extensive research and development activities [6]. This is partly due to its nature, wherein power generation is limited only to the time when sunlight is available. Despite its high costs, solar energy has become more widely applied; the solar PV industry's combined global revenue alone was estimated at US\$37 billion in 2008 [7]. However, any decrease in the efficiency of any solar power generation throughout its life cycle is undesirable because of its high capital cost. PV cells, for instance, may last for only about 25 years, and it takes approximately up to six years [8] to generate an amount equivalent to the energy consumed in its manufacturing processes. One significant factor that can contribute to a drop in the efficiency of solar panels is reduction of light irradiation, which can be for many reasons, such as accumulation of dust or algae on the panel $[9,10]$.

Variation of sunlight irradiation due to the sun's declination, which varies with the seasons, is another reason for reduction in light irradiation on solar panels [11]. The nature of this problem may vary by geographical location. Because of the high capital cost of solar power generation systems, economic considerations are critical, and this involves estimation of the potential amount of power that can be generated, the payback period, lifespan, etc., typically measured by average data [12]. Hadi et al. [13] suggested that the payback period for the usage of a solar PV system would be at least seven years, although, in their calculations, a constant (average) value of annual solar insolation of 2,080 $\mathrm{kWh} / \mathrm{m}^{2} / \mathrm{yr}$ was used, based on the work of previous researchers $[14,15]$. The calculation could be different if factors such as solar insolation were taken into account. Nevertheless, any variation of solar irradiation due to the sun's declination would result in belowaverage system operation. Making up for the deficiencies would require the use of a backup power system, which might eventually increase the overall cost of operation. Hence, more careful planning would be required, considering the local seasonal data of solar irradiation. Unfortunately, seasonal data are both expensive and difficult to obtain in many countries, including Kuwait. Although studies on solar irradiation were reported, for example in the work by Al-Enezi et al. [16], these studies only estimated solar radiation in Kuwait through a readily developed model. In a different work, Ghoneim and Abdullah [17] conducted a feasibility study of solar heating by using TRNSYS. The objective of this work was to characterize solar irradiation in Kuwait by measuring irradiance and comparing data of selected time periods in two different extreme seasons. The findings from this work can be used to decide if a more comprehensive measurement involving a longer period of time is required.

\section{METHODOLOGY}

The study was conducted at $\mathrm{Al}$ Abdali solar farm $\left(30.018^{\circ} \mathrm{N}, 47.712^{\circ} \mathrm{E}\right)$ located about 80 $\mathrm{km}$ north of Kuwait City. The solar farm, about $23 \mathrm{~m}$ above mean sea level, was also approximately $4 \mathrm{~km}$ from the border with Iraq. The location had about 10 hours of sunlight during the winter and 14 hours in the summer. A Sunshine Pyranometer Type SPN1, as shown in Figure 1, was used to measure solar irradiance as well as irradiance by the earth's surface due to reflection of sunlight. Table 1 shows the basic specifications of the pyranometer. The instrument was connected to a data logger to enable unmanned continuous measurements. In order to avoid inaccuracy due to shading, the instrument was mounted on flat ground, away from buildings or any tall structures. The instrument 
was mounted on a tubular beam attached to a tall pole, such that it was at a height of 2 meters from the ground and $0.8 \mathrm{~m}$ away from the pole.

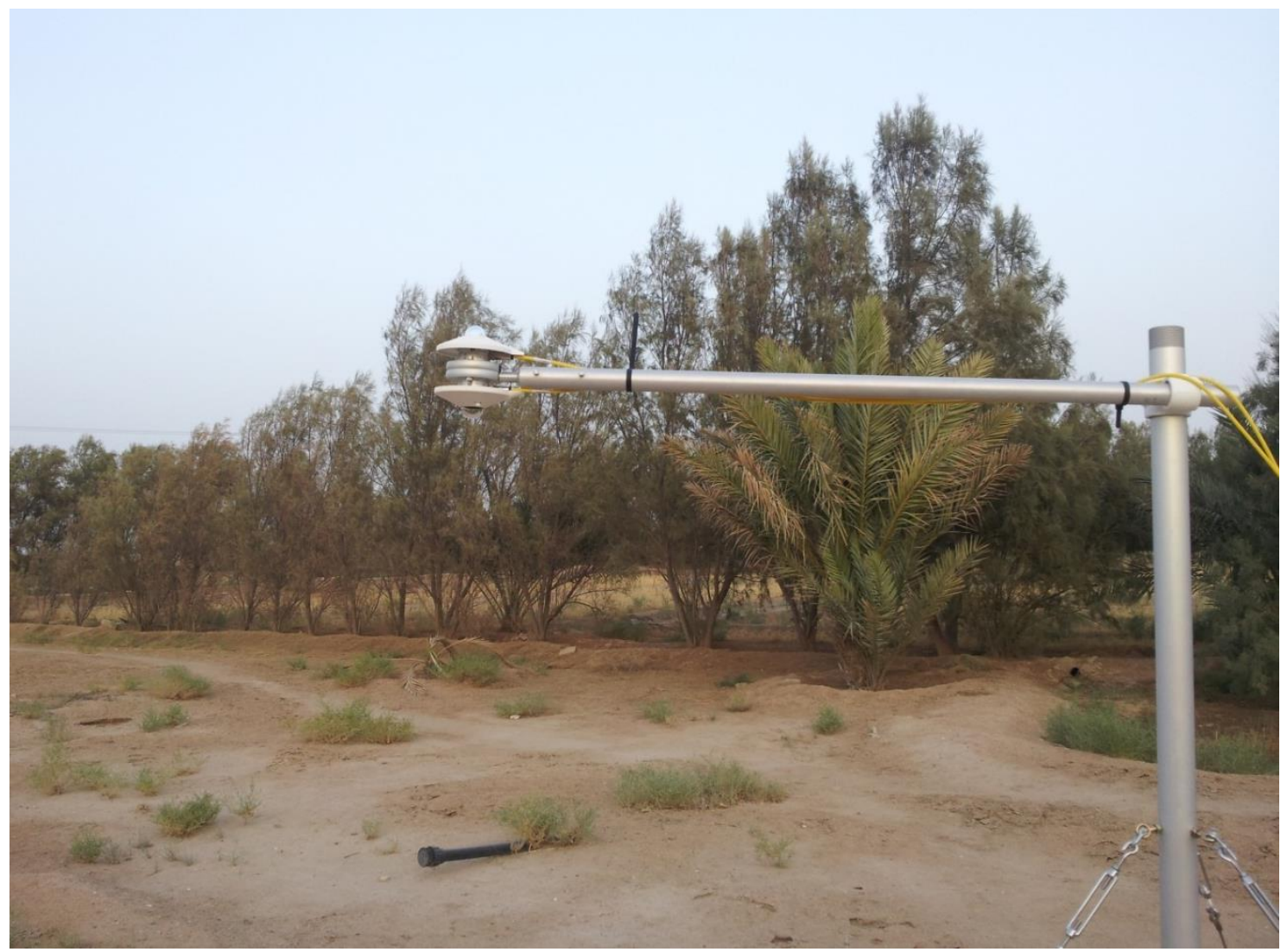

Figure 1. The pyranometer at site.

Table 1. Basic specification of the pyranometer.

\begin{tabular}{ll}
\hline & $\pm 5 \%$ Daily integrals \\
Overall accuracy & $\pm 5 \% \pm 10 \mathrm{~W} \cdot \mathrm{m}^{-2}$ hourly averages \\
& $\pm 8 \% \pm 10 \mathrm{~W} \cdot \mathrm{m}^{-2}$ individual readings \\
\hline Resolution & $0.6 \mathrm{~W} \cdot \mathrm{m}^{-2}=0.6 \mathrm{mV}$ \\
Range & 0 to $>2000 \mathrm{~W} \cdot \mathrm{m}^{-2}$ \\
Analogue output sensitivity & $1 \mathrm{mV}=1 \mathrm{~W} \cdot \mathrm{m}^{-2}$ \\
Analogue output range & $0-2500 \mathrm{mV}$ \\
Sunshine status threshold & $120 \mathrm{~W} \cdot \mathrm{m}^{-2}$ in the direct beam \\
Temperature coefficient & $\pm 0.02 \%$ per ${ }^{\circ} \mathrm{C}$ typical $(-20$ to \\
& $\left.+70^{\circ} \mathrm{C}\right)$ \\
Temperature range & -40 to $+70^{\circ} \mathrm{C}$ \\
\hline
\end{tabular}

The radiation data were measured at five-minute intervals for at least three consecutive days ( 24 hours per day) during the summer and winter. Such measurements were to allow for a comparison of day-to-day variation in the trend of irradiation during 
each season. The pyranometer was cleaned daily to ensure that its cover was free from light obstruction particles like sand and dust.

\section{RESULTS AND DISCUSSION}

The measurements in the summer and winter were conducted on 21-23 June 2013 and 922 December 2013, respectively. The duration in winter was longer than initially planned because the day-to-day variations were found to be significant. Figure 2 shows a typical temporal variation of irradiation throughout a day in summer, comprising solar incidence and surface reflection (from the earth's surface). As shown in Figure 2, solar incidence was first detected at about 5:00, around the time of sunrise, after which the amount of irradiance increased steadily until reaching a peak value (around $0.38 \mathrm{~kW} / \mathrm{m}^{2}$ ) at about 11:00. The irradiation due to solar incidence started to decrease at an approximately constant rate after about 13:00. The pattern for irradiation due to surface reflection is shown in Figure 2 to be almost identical to that due to solar incidence, although the peak value (around $0.13 \mathrm{~kW} / \mathrm{m}^{2}$ ) occurred later, at about 12:00. After around sunset, irradiation by solar incidence and surface reflection is shown to be diminished.

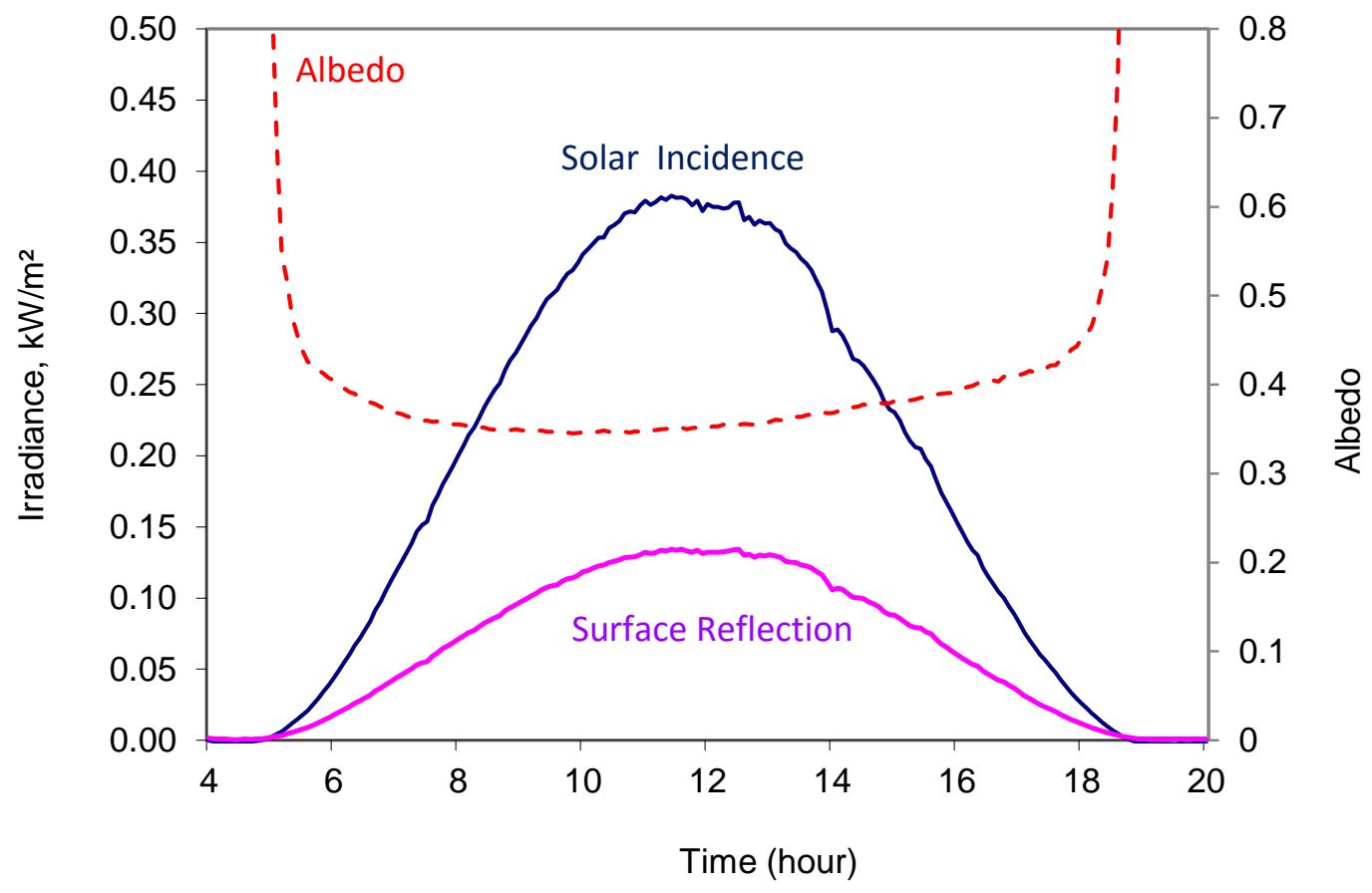

Figure 2. Typical daily variation in summer.

Related to irradiation due to surface reflection is albedo, which is the ratio of surface reflection to solar incidence. In Figure 2, albedo is represented by the U-shaped curve. The values of albedo are extremely high at the times of sunrise and sunset. This could be misleading, given that the denominator in the calculation for albedo would be low at those times. The more appropriate values of albedo lie at the time when it is quite constant (almost horizontally, as depicted in Figure 2): i.e., between 6:00 and 18:00. Albedo implies how strongly the earth reflects sunlight back to the atmosphere, and is 
highly relevant for studies related to global warming and greenhouse gases. However, since albedo is beyond the primary interest of this paper, it is not discussed further.

\section{Summer}

Figure 3 shows the temporal variation of irradiance during the summer on 21-23 June 2013. The data were collected starting from midnight at intervals of 5 minutes until about 18:00 on the third day. The measurement on the third day was slightly shorter for a technical reason, although this did not affect the purpose of the study. The figure shows that every day the first recordable irradiance started at about 5:00 am and the last occurred at around 18:45, and these were in tandem with the sun's positions (sunrise and sunset).

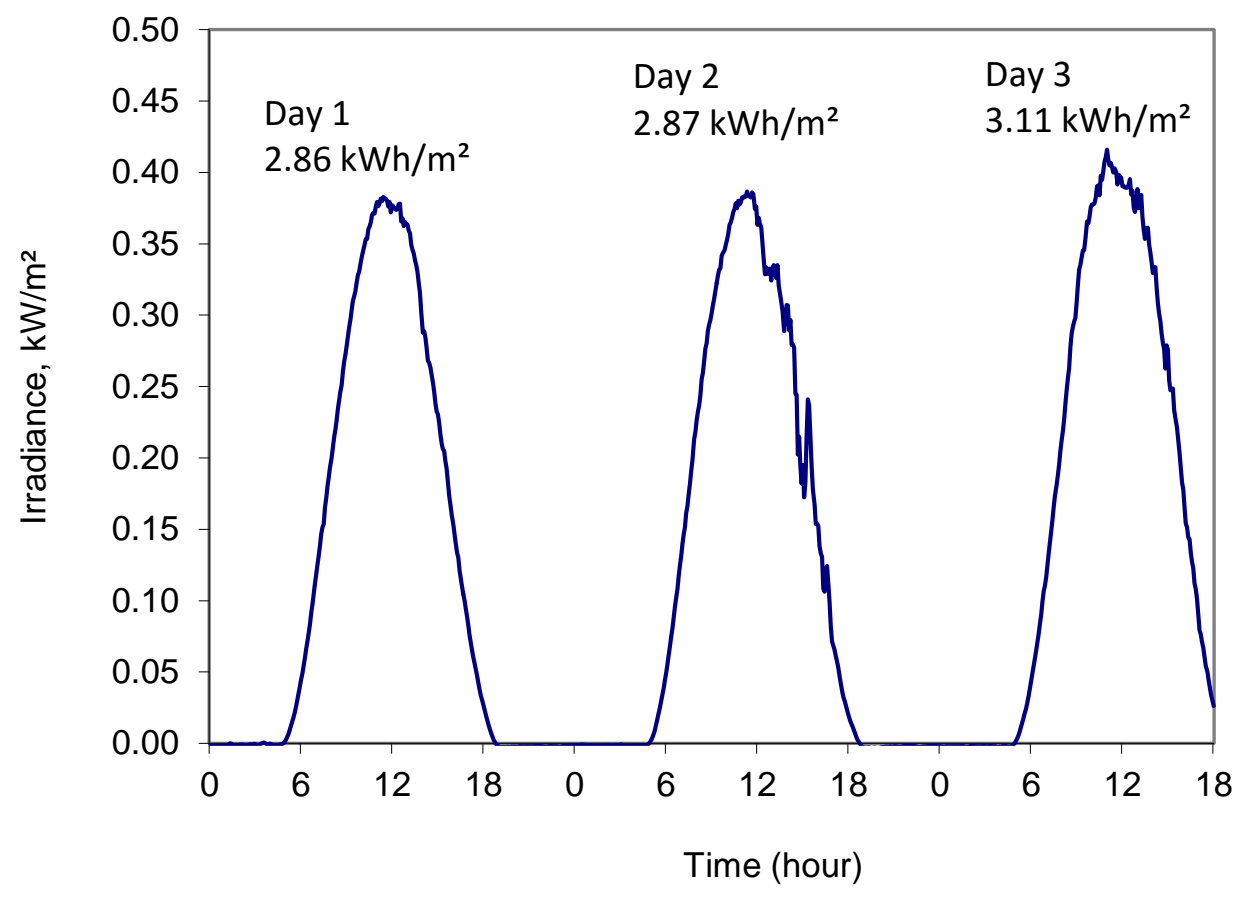

Figure 3. Variation of irradiance in the summer.

In general, the rise in irradiance is shown in the figure to be quite steady at a rate of $0.071 \mathrm{~kW} / \mathrm{m}^{2}$ per hour. The peak irradiances are shown to occur at between 11:00 and 11:30, with peak values of between 0.38 and $0.41 \mathrm{~kW} / \mathrm{m}^{2}$. Generally, the differences in the day-to-day irradiance are shown in Figure 3 to be small. This is supported by the graph in Figure 4, in which the daily irradiance distributions are superimposed based on time of day. As shown in both Figures 3 and 4, the fluctuations and variation in the measurements occurred between 12:00 and 16:00, although the differences are shown to be small. The maximum deviation in the day-to-day results is about $0.1 \mathrm{~kW} / \mathrm{m}^{2}$. The reason for the fluctuations in the results is unclear, although the authors would suggest that it could be due to the presence of light cloud, which is common in the afternoon due to the evaporation of water. Another possible reason could be the occurrence of sandy wind which intermittently obstructs the light path from the sun. The total energy collected on each day is also shown in Figure 3. The three-day average irradiance energy is 2.95 $\mathrm{kW} / \mathrm{m}^{2}$ and the standard deviation is $0.14 \mathrm{~kW} / \mathrm{m}^{2}(4.8 \%)$, which is small. The small deviation in irradiance implies that the weather is consistently clear in the summer at the test site, with the absence or minimum presence of clouds or suspended sand dust [16]. 


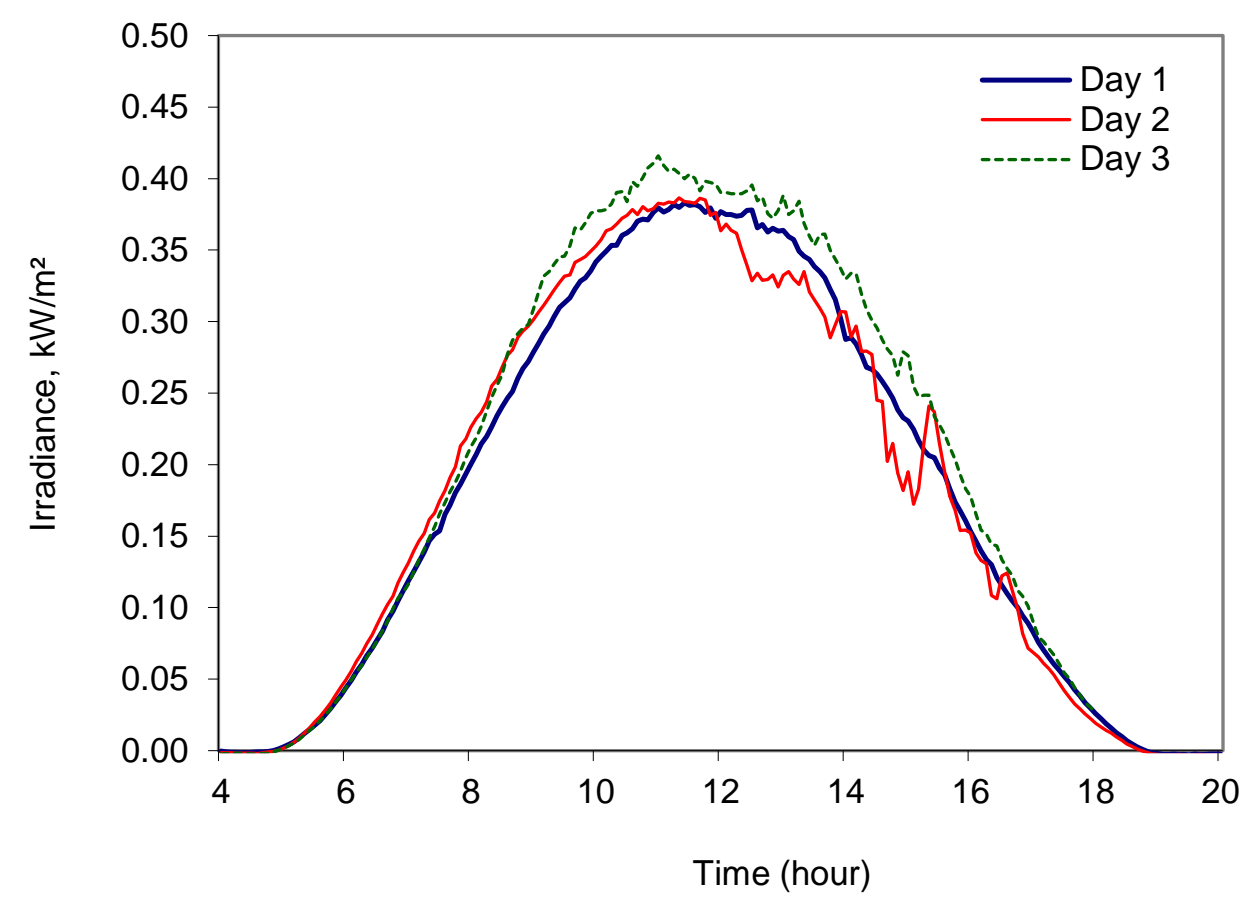

Figure 4. Day-to-day variation in irradiance in the summer.

\section{Winter}

Figure 5 shows the temporal variation of irradiance during the winter on 10-12 December 2013. The data were collected in the same manner as in the summer, starting from midnight for 72 hours. Generally, the figure shows that every day the first recordable irradiance started at about 6:30 and lasted to around 17:00, which tallied with the sunrise and sunset. It is clearly shown in the figure that the graphs display significant fluctuations compared to those in the summer, and this is suggested as being due to the changing weather conditions at the time of measurements. The peak irradiances for the three days occurred consistently at around 12:00, although the values are shown to be significantly different, i.e., between 0.25 and $0.30 \mathrm{~kW} / \mathrm{m}^{2}$. The total energy collected on each day is shown in Figure 5, ranging between 0.78 and $1.51 \mathrm{~kW} / \mathrm{m}^{2}$. It is interesting to note that, although the highest recordable irradiance occurred on Day 2, the energy collected for the same day was the lowest. The three-day average irradiance energy is $1.15 \mathrm{kWh} / \mathrm{m}^{2}$ and the standard deviation is $0.36 \mathrm{kWh} / \mathrm{m}^{2}(31.7 \%)$, which is very large. In comparison with the results in summer, the average collected energy by irradiance in winter is about $61 \%$ less. This implies that the collectable energy in the winter is significantly low and thus may require the operation of a backup power supply in order to make up for the deficiency.

The differences in the day-to-day irradiance are shown in Figure 5 to be obvious, and this is verified by the graph in Figure 6, in which the daily irradiance distributions are superimposed based on time of day. As shown in Figure 6, the differences in irradiance are small only in the first hour after sunrise and one hour before sunset, probably due to the influence of long wavelength light around those periods of time. The variation in the measurements is greatest during the middle of the day. The trends on Day 2 demonstrate a greater difference than those on other days. The maximum deviation in the day-to-day results is about $0.23 \mathrm{~kW} / \mathrm{m}^{2}$. The variations and fluctuations could be due to the changing weather in winter. During this work, it was decided that the measurement of irradiance 
for winter should be prolonged for another 11 days in view of the fluctuations and inconsistency of the irradiance pattern shown in Figures 5 and 6. The method of measurement was maintained, and the results are shown in Figure 7 in the form of variation of irradiance for a total of 14 consecutive days (including the first three days). From the figure, it is clear that fluctuations and day-to-day variations prevail, as indicated earlier in Figure 5.

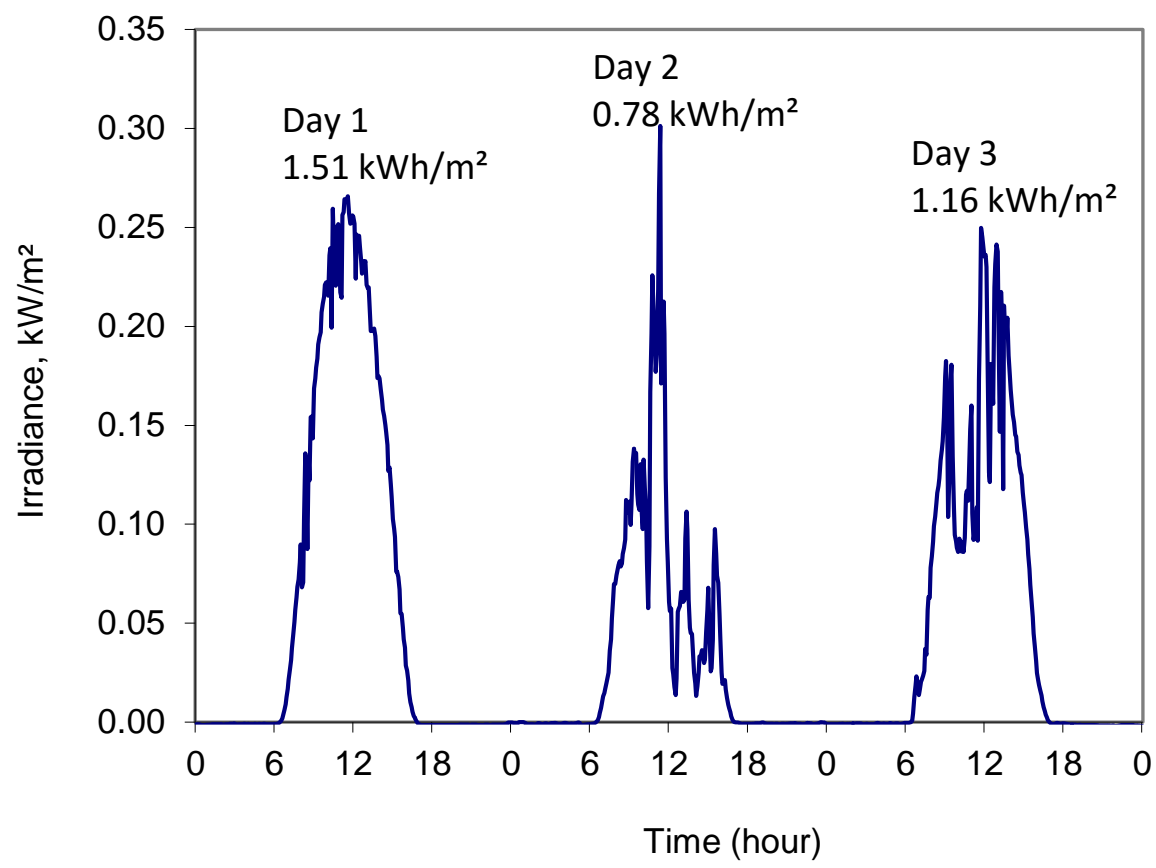

Figure 5. Variation of irradiance in the winter.

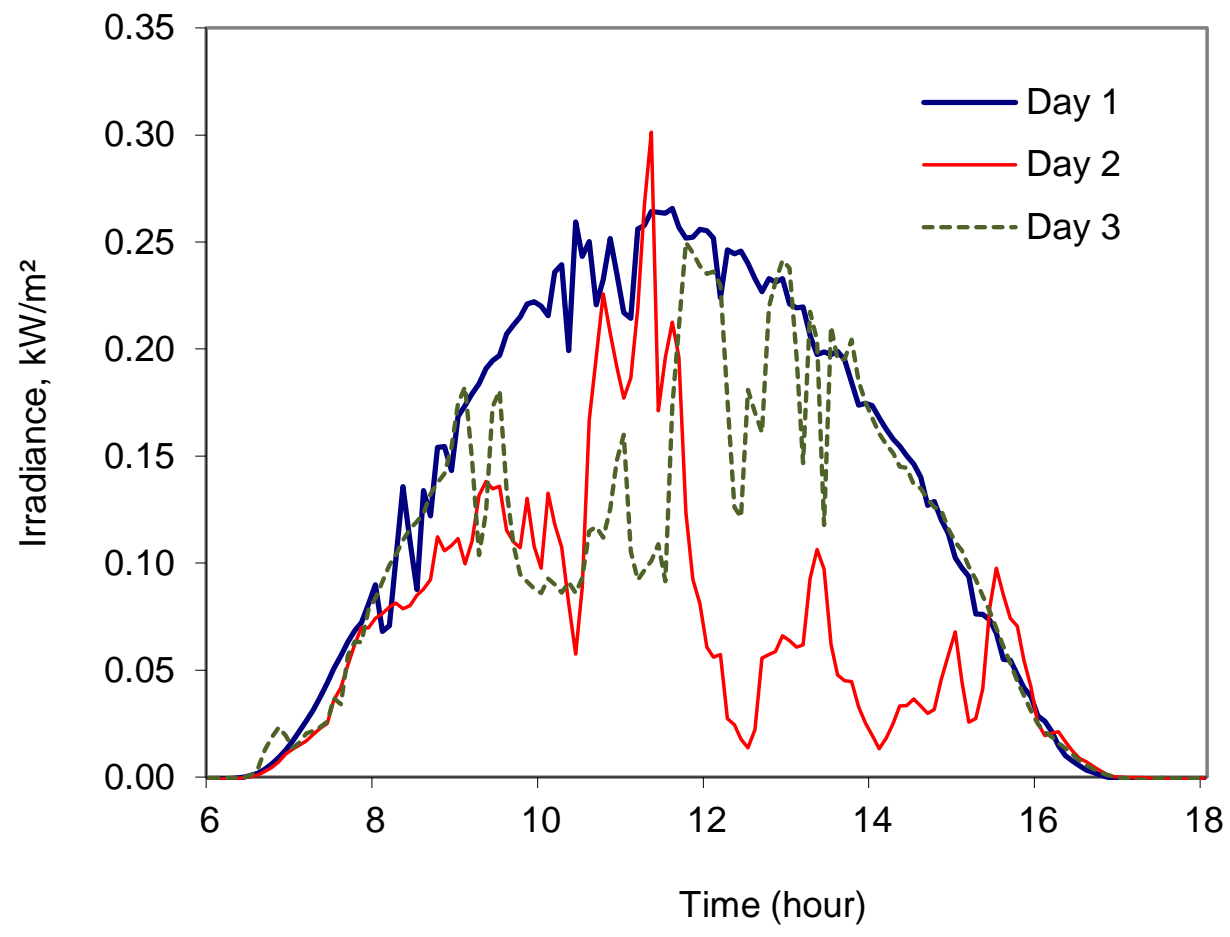

Figure 6. Day-to-day variation in irradiance in the winter (3 days). 


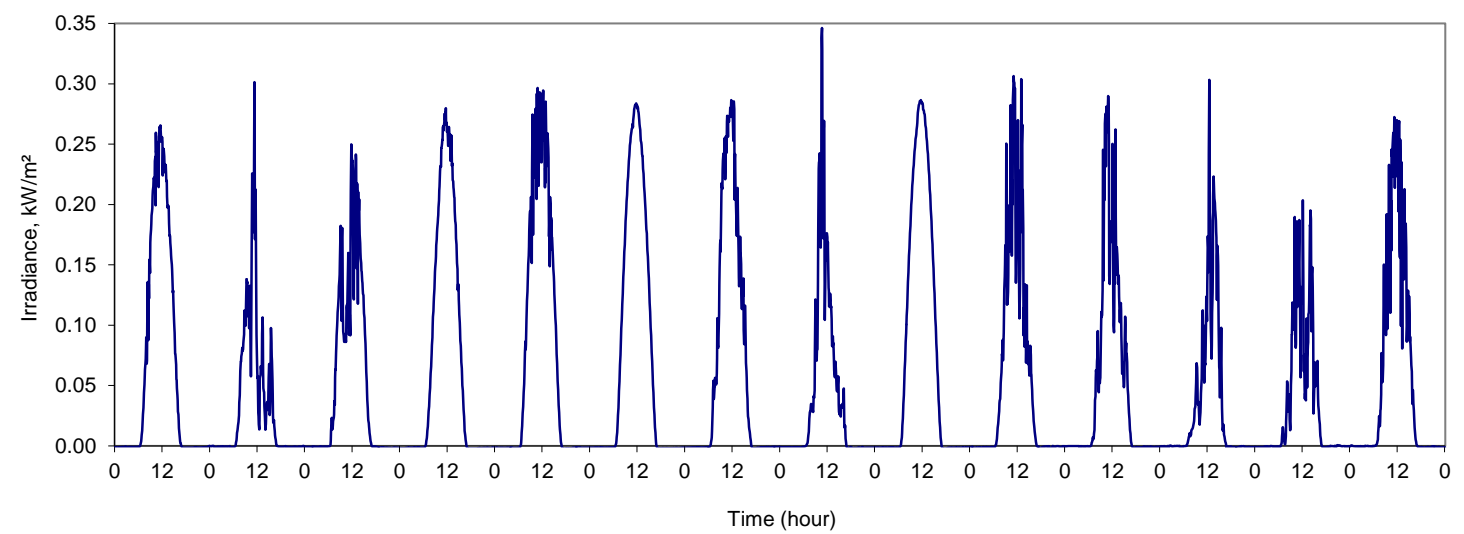

Figure 7. Day-to-day variation in winter (14 days) as additional observation.

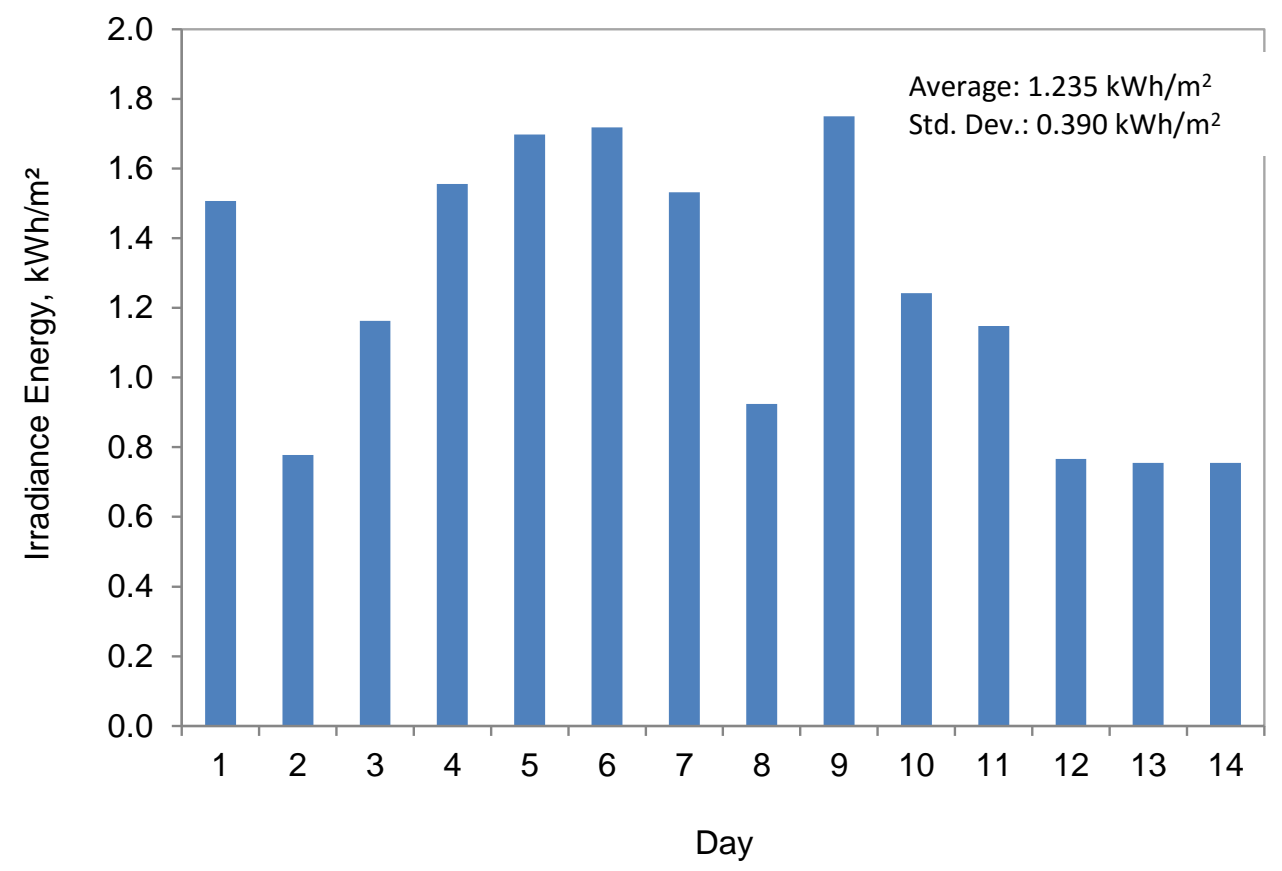

Figure 8. Daily distribution of irradiance energy in the winter.

The distribution of daily average irradiance energy is presented by the histogram in Figure 8. The average irradiance energy is $1.235 \mathrm{kWh} / \mathrm{m}^{2}$ and the standard deviation is $0.390 \mathrm{kWh} / \mathrm{m}^{2}(31.6 \%)$, which is very large and consistent with the findings presented for Figure 6. Thus, the results in Figures 7 and 8 strengthen the suggestion that solar irradiation in Kuwait is disrupted in the winter season and thus would affect power generation performance. Due to large fluctuations, the amount of solar energy that can be harvested in the winter is less than in the summer. Thus, a backup power system will have to perform extra work during winter, therefore incurring higher operational costs [18].

\section{CONCLUSIONS}

A study was conducted to investigate the trends of solar irradiance in Kuwait in two different seasons: summer and winter. The results in the two seasons were compared in 
order to understand the nature of irradiation at the site. Overall, irradiation in the summer was found to be significantly greater than that in the winter. Thus, proper attention has to be given to sizing solar energy conversion equipment for the specific place of study. Furthermore, the following conclusions can be drawn:

1. The day-to-day variation of irradiance in the summer was found to be small with a standard deviation of irradiance energy of only $4.8 \%$. On the other hand, the variation was significantly larger in the winter with a standard deviation of over $31 \%$, or 6.5 times higher than in the summer. This suggests that the operation of solar energy systems in winter would face significant day-to-day fluctuations. In the case of electric or thermal power production by means of solar energy, this could lead to complications in operation due to the unsteady supply of energy from the source.

2. The amount of irradiance energy in the winter was observed to be up to $61 \%$ less than in the summer. Consequently, this would necessitate frequent operation of backup power systems (such as diesel engines) in order to make up for the electrical power load demand.

The findings from this work were the result of measurements within a very short period of time, as the primary intention was to study the general trend. Further study should be conducted for a longer period of at least a year, in order to obtain more convincing results. Diversification of sites of study would also help to understand the trends better.

\section{ACKNOWLEDGMENTS}

The authors would like to express their thanks to the Director of the Meteorological Department, Mohammed Karam, Department and Climatology Superintendent Dr. Hassan Al-Dashti for their supports in this work.

\section{REFERENCES}

[1] Riza R, Ariwahjoedi B, Sulaiman SA. On the numerical exploration of zerodimensional greenhouse model using Newton-Raphson and steepest descent methods. International Journal of Environmental Science and Development. 2011;2:233-8.

[2] Sulaiman S, Murad S, Ibrahim I, Abdul Karim Z. Study of flow in air-intake system for a single-cylinder go-kart engine. International Journal of Automotive and Mechanical Engineering. 2010;1:91-104.

[3] Kareem M, Habib K, Sulaiman S. Comparative study of single pass collector and double pass solar collector filled with porous media. Asian Journal of Scientific Research. 2013;6:445-55.

[4] Mahendran M, Sharma KV. Performance evaluation of evacuated tube solar collector using water-based titanium oxide (Tio2) nanofluid. Journal of Mechanical Engineering and Sciences. 2012;3:301-10.

[5] Al-Kayiem H, Md Yunus Y. Drying of empty fruit bunches as wasted biomass by hybrid solar-thermal drying technique. Journal of Mechanical Engineering and Sciences. 2013;5:652-61.

[6] Mahendran M, Lee G, Shahrani A, Bakar R, Kadirgama K, Amir A, et al. Diurnal pattern and estimation of global solar radiation in East Coast Malaysia. International Journal of Automotive and Mechanical Engineering. 2013;8:116275. 
[7] Solar Power Information. Solar panels. www.solarpower2day.net/solar-panels/. 2009.

[8] Kannan R, Leong K, Osman R, Ho H, Tso C. Life cycle assessment study of solar PV systems: an example of a $2.7 \mathrm{~kW}$ p distributed solar PV system in Singapore. Solar Energy. 2006;80:555-63.

[9] Sulaiman SA, Hussain HH, Leh N, Razali MS. Effects of dust on the performance of PV panels. World Academy of Science, Engineering and Technology. 2011;58:588-92.

[10] Sulaiman SA, Singh AK, Mokhtar MMM, Bou-Rabee MA. Influence of dirt accumulation on performance of PV panels. Energy Procedia. 2014;50:50-6.

[11] Majid Z, Razak A, Ruslan M, Sopian K. Characteristics of solar thermal absorber materials for cross absorber design in solar air collector International Journal of Automotive and Mechanical Engineering. 2015;11:2582-90.

[12] Husain NS, Zainal NA, Singh BSM, Mohamed NM, Nor NM. Integrated PV based solar insolation measurement and performance monitoring system. Humanities, Science and Engineering (CHUSER), 2011 IEEE Colloquium on: IEEE; 2011. p. 710-5.

[13] Hadi MA, Abdel-Razek RH, Chakroun WM. Economic assessment of the use of solar energy in Kuwait. Global Journal of Business Research. 2013;7:73-82.

[14] Ramadhan M, Hussain A, Behbehani D. The prospect of solar energy in the development of power stations in the state of Kuwait. Journal of Renewable Energy. 2012;2013.

[15] Alnaser W, Eliagoubi B, Al-Kalak A, Trabelsi H, Al-Maalej M, El-Sayed H, et al. First solar radiation atlas for the Arab world. Renewable Energy. 2004;29:1085107.

[16] Al-Enezi F, Sykulski J, Ahmed NA. Visibility and potential of solar energy on horizontal surface at Kuwait area. Energy Procedia. 2011;12:862-72.

[17] Ghoneim A, Abdullah A. Feasibility Study of Solar Heating and Cooling Systems in Kuwait. ANZSES. 2003:239-48.

[18] Redflow. Energy storage and diesel generator run-time reduction, energy safe victoria: remote area power supply (raps) trial. http://redflow.com. 